\title{
ESTADO DA ARTE DA PESQUISA (AUTO)BIOGRÁFICA: UMA ANÁLISE DO PORTAL DE PERIÓDICOS CAPES
}

MICHAEL DAIAN PACHECO RAMOS

Universidade do Estado da Bahia (UNEB)

RITA DE CÁSSIA MAGALHÃES DE OLIVEIRA

Universidade do Estado da Bahia (UNEB)

MARIA RITA SANTOS

Universidade do Estado da Bahia (UNEB)

O presente artigo tem como objeto de estudo o estado da arte acerca da pesquisa (Auto)biográfica nas publicações do portal de periódicos da CAPES. Nossos objetivos foram: mapear a produção do conhecimento no campo da pesquisa (Auto)biográfica; analisar o campo da pesquisa (Auto)biográfica, a fim de contribuir com o debate de questões teórico-metodológicas; e relacionar os dados identificados nos resumos dos artigos com outros estudos do campo da pesquisa (Auto)biográfica. Realizamos um estudo do tipo estado da arte, construído por meio de levantamento de artigos no portal de periódicos do Centro de Aperfeiçoamento de Pessoal de Nível Superior (CAPES). Os resultados apontam que: 1) há uma ampliação do horizonte das opções teóricas, das direções metodológicas e das escolhas técnicas que a pesquisa (Auto)biográfica vem realizando no cenário atual; 2) a maioria dos trabalhos está vinculada ao Brasil, ademais encontramos artigos de países da América do Sul, América Central e Europa; 3) houve uma articulação com múltiplos campos do conhecimento, em especial das Ciências Humanas, Filosofia, Educação, Saúde, Ciências Sociais e Geografia; 4) prevalecem as narrativas/relatos (auto) biográficos orais e escritos, as história de vida e os memoriais de formação.

Palavras-chave: Pesquisa (auto)biográfica. Estado da arte. Educação.

STATE OF THE ART OF (AUTO) BIOGRAPHICAL RESEARCH: AN ANALYSIS OF THE PORTAL OF JOUNALS CAPES

The present article has as object of study the state of the art of the (Auto) biographical research in the publications of the portal of journals CAPES. Our objectives were: 1) To map the production of knowl- 
edge in the field of (auto) biographical research; 2) To analyze the field of (auto) biographical research in order to contribute to the debate of theoretical and methodological issues and; 3 ) To relate the data identified in the summaries of the articles with other studies in the field of (auto) biographical research. We conducted a state-ofthe-art study, which was constructed by means of a research of articles in the journal portal of the Center for the Improvement of Higher Education Personnel (CAPES). The results showed that: 1) there is an expansion in the horizon of the theoretical options, the methodological directions and the technical choices that the (auto) biographical research has been carrying out in the current scenario; 2) most of the works are linked to Brazil, in addition we found articles from countries of South America, Central America and Europe; 4) There was an articulation with multiple fields of knowledge in particular of the Human Sciences, Philosophy, Education, Health, Social Sciences and Geography; 5) Prevails oral and written (auto) biographical narratives/reports, life stories and formation memorials.

Keywords: (Auto)biographical research. State of art. Education.

\section{ESTADO DEL ARTE DE INVESTIGACIÓN (AUTO) BIOGRÁFICA: UN ANÁLISIS DEL PORTAL DE REVISTAS DE LA CAPES}

El presente artículo tiene como objeto de estudio el estado del arte acerca de la investigación (auto)biográfica en las publicaciones del portal de revistas de la CAPES. Nuestros objetivos fueron: 1) Mapear la producción del conocimiento en el campo de la investigación (auto)biográfica; 2) Analizar el campo de la investigación (auto)biográfica a fin de contribuir con el debate de cuestiones teórico-metodológicas y; 3) Relacionar los datos identificados en los resúmenes de los artículos con otros estudios del campo de la investigación (auto)biográfica. Realizamos un estudio del tipo estado del arte, construido por medio del levantamiento de artículos en el portal de periódicos del Centro de Perfeccionamiento de Personal de Nivel Superior (CAPES). Los resultados apuntan que: 1) hay una ampliación del horizonte de las opciones teóricas, de las direcciones metodológicas y de las opciones técnicas que la investigación (auto)biográfica viene realizando en el escenario actual; 2) la mayoría de los trabajos están vinculados a Brasil, además encontramos artículos de países de América del Sur, Centroamérica y Europa; 4) hubo una articulación con múltiples campos del conocimiento en especial de las Ciencias Humanas, Filosofia, Educación, Salud, Ciencias Sociales y Geografia; 
5) prevalece las narrativas / relatos (auto)biográficos orales y escritos, las historias de vida y los memorias de formación.

Palabras clave: Investigación (auto)biográfica. Estado de la arte. Educación.

\section{INTRODUÇÃO}

O presente artigo tem como objeto de estudo o estado da arte sobre a pesquisa (Auto) biográfica, construído por meio de resultados do levantamento de artigos em relação a esse campo de pesquisa, no portal de periódicos do Centro de Aperfeiçoamento de Pessoal de Nível Superior (CAPES), com o intuito de colaborar com os estudos desse campo de pesquisa e formação.

Os objetivos deste artigo foram: 1) mapear a produção do conhecimento no campo da pesquisa (Auto)biográfica; 2) analisar o campo da pesquisa (Auto)biográfica, a fim de contribuir com o debate de questões teórico-metodológicas; e 3) relacionar os dados identificados nos resumos dos artigos com outros estudos do campo da pesquisa (Auto)biográfica.

A motivação para iniciar a escrita deste texto deu-se a partir da solicitação de um trabalho de conclusão da disciplina "Pesquisa (Auto)biográfica: perspectivas metodológicas", ministrada pelos professores Elizeu Clementino de Souza e Sandra Magalhães. Essa disciplina pertence ao quadro de componentes curriculares optativos do Doutorado em Educação e Contemporaneidade, vinculado ao Programa de Pós-Graduação em Educação e Contemporaneidade (PPGEDUC) da Universidade do Estado da Bahia (UNEB).

Sobre os estudos denominados de estado da arte ou estado do conhecimento, podemos afirmar que possuem características:

Definidas como de caráter bibliográfico, elas parecem trazer em comum o desafio de mapear e de discutir uma certa produção acadê- mica em diferentes campos do conhecimento, tentando responder que aspectos e dimensões vêm sendo destacados e privilegiados em diferentes épocas e lugares, de que formas e em que condições têm sido produzidas certas dissertações de mestrado, teses de doutorado, publicações em periódicos e comunicações em anais de congressos e de seminários. Também são reconhecidas por realizarem uma metodologia de caráter inventariante e descritivo da produção acadêmica e científica sobre o tema que busca investigar, à luz de categorias e facetas que se caracterizam enquanto tais em cada trabalho e no conjunto deles, sob os quais o fenômeno passa a ser analisado. (FERREIRA, 2002, p. 257)

Assim, para Ferreira (2002), as pesquisas de estado da arte se debruçam sobre dados bibliográficos, como leitura de título, palavraschave e resumos, levando o pesquisador a tramitar por dois momentos distintos. 0 primeiro é aquele onde ele interage com a produção acadêmica, quantificando e identificando os dados bibliográficos; o segundo momento é aquele em que o pesquisador inventaria essa produção, aponta tendências, percebe as ênfases, identifica as escolhas metodológicas e teóricas, e aproxima ou distancia os trabalhos entre si.

Dessa forma, inspiramo-nos também em outros estudos que realizaram um esforço semelhante de mapear e refletir sobre a produção do conhecimento relacionada ao campo da pesquisa (Auto)biográfica, a saber: Stephanou (2008), Souza; Sousa e Catani (2008) e Mignot e Souza (2015). Assim, em concordância com Mignot e Souza (2015), observamos que: 
[...] se inscreve no mesmo esforço já empreendido de mapeamento ou do que se convencionou chamar 'estado da arte', que busca visibilizar modos de produção no campo da pesquisa (auto)biográfica no Brasil, com destaques para apreensões de novos contornos, avanços e configurações que tais estudos têm assumido numa rede de pesquisa nacional e internacional, entre grupos de pesquisas, associações e investigadores de diferentes campos disciplinares. (MIGNOT; SOUZA, 2015, p. 12)

Nesse sentido, este trabalho converge para:

[...] o crescimento vertical do campo da pesquisa (auto)biográfica, entendido como elevação substantiva e crescente dos niveis de qualidade da produção e a expansão horizontal, significando o alargamento do território ocupado por pessoas e instituições envolvidas com esse tipo de pesquisa (individual ou em colaboração), no Brasil e em nossas conexões fora dele. (MIGNOT; SOUZA, 2015, p. 13, grifo dos autores)

Contribuiu também para a nossa reflexão o estudo de Souza, Sousa e Catani (2008), autores que procuraram compreender as peculiaridades das apropriações brasileiras de trabalhos articulados a "histórias de vida em formação" e a "metodologias autobiográficas", no primeiro e segundo Congresso Internacional sobre Pesquisa (Auto)biográfica (CIPA), realizado em Porto Alegre (2004) e Salvador (2006).

De acordo com Souza, Sousa e Catani (2008):

As análises que produzem mapeamentos, "estado da arte" ou grandes quadros de caracterização de pesquisas num determinado território temático ou disciplina têm proliferado bastante no nosso país, nos últimos anos. Estratégia fecunda para ordenar e permitir distinções, agrupamentos e identificação de problemas, perspectivas ou questões. No entanto, esses modos de trabalho podem chegar a um esgotamento relativo, caso não se complementem por outros investimentos analíticos. Ao se propor a examinar as produções apresentadas nos Congressos de Pesquisa (Auto)biográfica no Brasil, busca-se sugerir indagações que ajudem na construção de novos modos de trabalho e na validação dos já existentes. A propósito dos estudos históricos-educacionais e comparados, já se sustentou a necessidade de ultrapassar os limites dos mapeamentos na direção (e de algum modo, no retorno) a questões ligadas, simultaneamente, à análise das condições de produção e da escrita das investigações (CATANI, 2000 e 2006). Considera-se que o mesmo movimento deva ser estimulado com relação aos estudos (auto) biográficos e às histórias de vida em formação. (SOUZA; SOUSA; CATANI, 2008, p. 33)

Stephanou (2008) aponta que a inspiração para seu estudo sobre o estado da arte, no campo da pesquisa (Auto)biográfica, se inicia com o tema do III Congresso Internacional sobre Pesquisa (Auto)Biográfica (CIPA): ${ }^{1}$

Motivada pelo tema '(Auto) Biografia: formação, territórios e saberes', especialmente pelas suas dimensões epistemológicas e metodológicas, dispus-me a uma aproximação aos estudos que, nos últimos anos, vêm sendo desenvolvidos no campo da Educação, seja em relação ao (auto) biográfico como método de pesquisa, seja como procedimento de formação e intervenção social. (STEPHANOU, 2008, p. 22)

Stephanou (2008) aponta, enquanto consideração de sua pesquisa, que há uma grande quantidade de estudos sobre memórias, história de vida, história oral, biografias e (auto) biografias, conjuntamente a um grande foco na formação docente, no campo da pesquisa da pós-graduação brasileira, especialmente no final da década de 1990 e até o início da década de 2010.

Ao apresentar as conclusões de Stephanou (2008), Mignot e Souza (2015) e Souza, Sousa e Catani (2008), entendemos que há espaços nesses trabalhos de estado da arte, no campo da pesquisa (auto)biográfica, que justificam a necessidade de nosso esforço de pesquisa, a saber: a) houve pesquisas com a base de dados no portal de periódicos da CAPES; b) houve

1 O III CIPA ocorreu em Natal, Rio Grande do Norte, Brasil no período de 14 a 17 de setembro de 2008. 
pesquisas somente no banco de teses e dissertações da CAPES e nos livros vinculados ao CIPA; c) não houve pesquisas com a base de dados de artigos e, sim, de livros, teses e dissertações; e c) utilizamos oito descritores da investigação (Auto)biográfica, tentando identificar o máximo de artigos vinculados a esse campo de pesquisa.

Partindo dessa problematização, compartilhamos de reflexões semelhantes às de Stephanou (2008) sobre os objetivos de um trabalho que tem como opção metodológica o estado da arte: a) somente inventariar, contabilizar e avaliar mecanicamente o conjunto de artigos reunidos? b) Quais os efeitos e o alcance deste estudo? E, finalmente: c) como podemos problematizar o que apontam os resumos dos artigos, diante da limitada e genérica constituição em que se apresentaram?

Optamos por mapear a produção do conhecimento registrada sob a forma de resumos dos artigos, junto ao portal de periódicos da CAPES, que é gerido pela Coordenação de Aperfeiçoamento de Pessoal de Nivel Superior (CAPES). No site do portal de periódicos da CAPES, podemos localizar os artigos por: data de publicação, tipo de material, coleção, tópico, idioma, assunto, autor(es), título do periódico, data inicial e final de publicação.

As informações coletadas sobre cada artigo foram cadastradas em uma ficha (Apêndice A), que contém os seguintes dados: título, autoria, ano de publicação, nome, número e volume do periódico, número total de páginas, instituição em que o periódico está vinculado, o resumo propriamente dito e as palavras-chave. Contudo, não foi possivel identificar todas as informações no portal de periódico da CAPES, o que nos levou a realizar uma busca, no próprio site de cada revista e/ou periódico. Ainda assim, apesar desse esforço complementar, algumas informações não puderam ser identificadas.
Realizamos a coleta dos artigos com oito descritores que se articulam ao campo da produção do conhecimento relacionado com a pesquisa (Auto)biográfica, a saber: 1) pesquisa (auto)biográfica; 2) pesquisa autobiográfica; 3) pesquisa biográfica; 4) abordagem (auto)biográfica; 5) abordagem autobiográfica; 6) abordagem biográfica; 7) narrativa(s) (auto)biográfica(s) e 8) narrativa(s) autobiográfica (s). Para todos os descritores, fizemos uma seleção de artigos, utilizando como critério de pesquisa, no portal de periódicos CAPES, o recurso da busca avançada e a opção "Qualquer" e também "No assunto", bem como a opção "é (exato)". Não utilizamos o indicador booleano "and" em nenhum descritor.

No conjunto do material apresentado por meio da pesquisa de busca avançada, utilizamos ainda como critério de seleção para nosso estudo somente os artigos relacionados à temática da área da Educação. Dessa forma, excluímos da amostra final dissertações, teses, livros e artigos repetidos e de outras áreas do conhecimento. Não houve delimitação de tempo para a seleção do material.

Observamos, na figura 1, a sequência do processo de coleta e seleção dos artigos no portal de periódico da CAPES.

O movimento para a seleção e a coleta dos artigos deu-se da seguinte forma: inicialmente, acessamos o portal de periódicos da CAPES pelo recurso "busca avançada", onde colocamos cada descritor individualmente e enumeramos a quantidade de material que se relacionava a cada descritor. Ao total da coleta com os oito descritores, encontramos 184 materiais relacionados ao campo da pesquisa (Auto)biográfica. Contudo, nosso critério de seleção foi somente artigos. Então, após a primeira coleta, utilizamos o recurso de filtro para coletar somente os artigos, excluindo livros, dissertações e teses, restando somente 110 artigos. 
Figura 1 - Organograma de coleta e seleção dos artigos no portal de periódicos da Capes

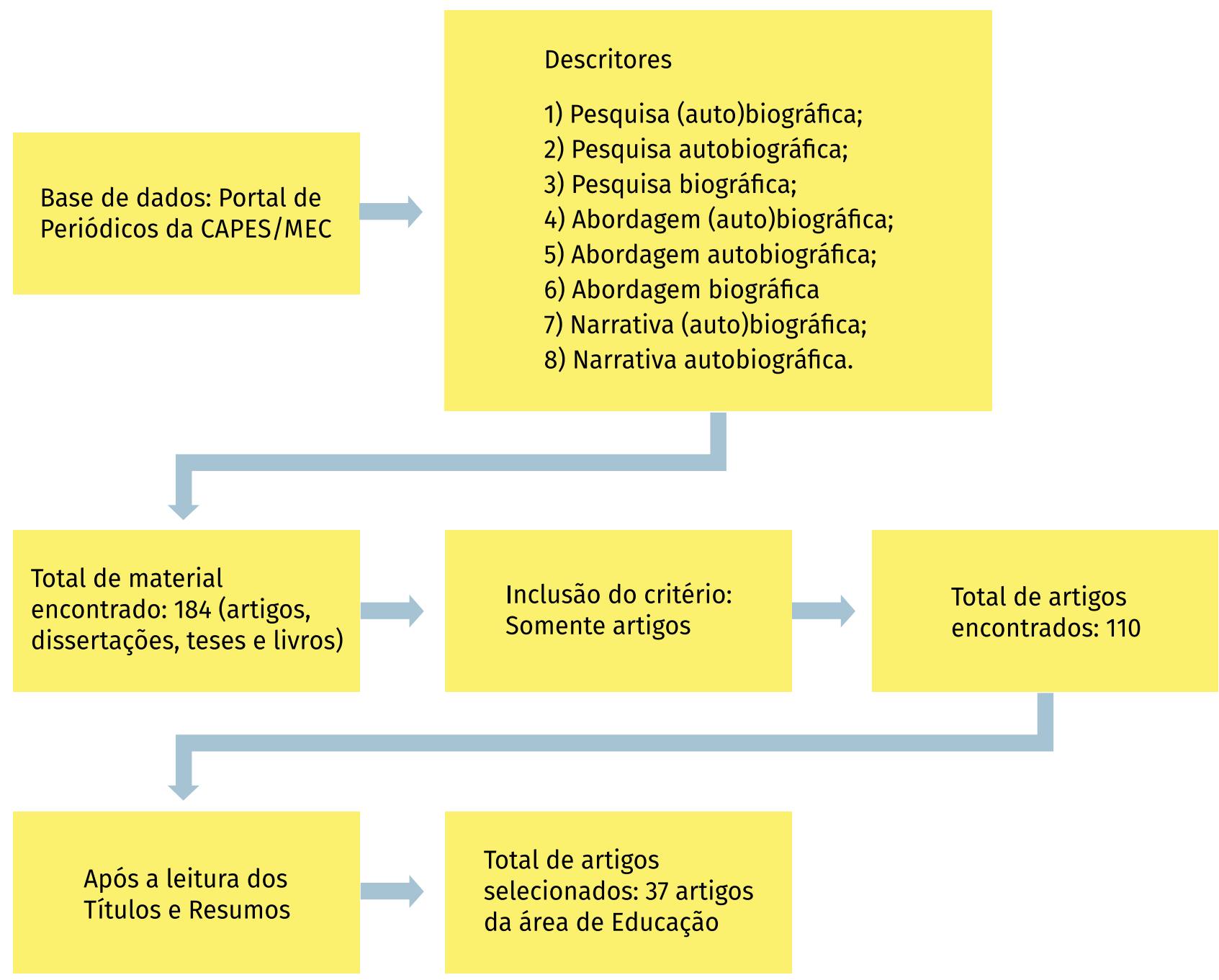

Fonte: Portal de periódicos CAPES, 2016.

Em um segundo momento da pesquisa, realizamos o preenchimento da ficha (Apêndice A), com os dados relacionados: título, autor, ano de publicação, nome do periódico, dados da publicação, resumo e palavras-chave dos 110 artigos identificados. Após o preenchimento das fichas, na leitura dos títulos e resumos, identificamos artigos repetidos. Nesse caso, realizamos um novo recorte, restando apenas 79 artigos. Por fim, selecionamos apenas os artigos relacionados com a área da Educação, restando somente 37 artigos. Esse quantitativo de 37 artigos foi nossa amostra final para a análise, conforme Apêndice B deste trabalho.

\section{Aproximações iniciais: o que a produção acadêmica aponta?}

Iniciando nossa análise sobre o campo da pesquisa (Auto)biográfica, iremos apresentar o mapeamento da distribuição quantitativa de cada descritor utilizado neste trabalho. A opção pela escolha de oito descritores para o campo da pesquisa (Auto)biográfica diz respeito aos diferentes tratamentos que os autores dão a este campo de pesquisa.

Na Tabela 1, a seguir, apresentamos a distribuição quantitativa e o percentual dos artigos em cada descritor utilizado. 
Tabela 1 - Distribuição dos descritores utilizados na pesquisa e a quantidade de artigos selecionados para a análise

\begin{tabular}{c|c|c}
\hline DESCRITOR & \multicolumn{2}{|c}{ TOTAL } \\
\hline Pesquisa (auto)biográfica & 8 & 21,7 \\
Pesquisa autobiográfica & 4 & 10,8 \\
Pesquisa biográfica & 7 & 18,8 \\
\hline Abordagem (auto)biográfica & 3 & 8,1 \\
\hline Abordagem autobiográfica & 1 & 2,7 \\
Abordagem biográfica & 3 & 8,1 \\
\hline Narrativa(s) (auto)biográfica & - & - \\
\hline Narrativa(s) autobiográfica & 11 & 29,8 \\
\hline Total & 37 & 100 \\
\hline
\end{tabular}

Fonte: Portal de Periódicos da CAPES, 2016.

Já vimos anteriormente que de um total de 184 produções (incluindo livros, dissertações e teses) restaram, após os critérios de seleção, apenas 37 artigos da área da Educação. Deste quantitativo, identificamos que o maior número de artigos foi encontrado, quando utilizamos o descritor narrativa(s) autobiográfica, com 11 artigos, representando cerca de $29,8 \%$ da amostra total. A segunda maior amostra, composta de oito artigos, está representada por 21,7\%, quando utilizamos o descritor pesquisa (auto)biográfica. Encontramos sete artigos, o equivalente a $18,8 \%$ do total, quando utilizamos o descritor pesquisa biográfica.

Ao utilizar os descritores pesquisa autobiográfica, encontramos quatro artigos (cerca de $10,8 \%$ ), já com os descritores abordagem autobiográfica e abordagem biográfica identificamos três artigos em cada um, represen- tando $8,1 \%$ da amostra total. Com o descritor abordagem autobiográfica, encontramos apenas um artigo (que representou $2,7 \% \mathrm{da}$ amostra). E, finalmente, ao utilizar o descritor narrativa(s) (auto)biográfica(s) não coletamos nenhum artigo.

Esses dados quantitativos também nos apresentam a preferência que os estudos, no campo da pesquisa (Auto)biográfica, têm em utilizar os prefixos auto ou (auto), para correlacionar o campo de estudo das narrativas, histórias de vida, biografia e história oral. Demonstra também o predomínio da utilização do termo "narrativa(s) autobiográfica(s)", que atualmente temos percebido a sua utilização em livros, revistas, eventos e congressos.

Outro aspecto que analisamos diz respeito ao ano de publicação dos artigos. A Tabela 2, a seguir, apresenta a distribuição da quantidade de artigos por ano de publicação. 
Tabela 2 - Distribuição da quantidade de artigos analisados por ano de publicação

\begin{tabular}{|c|c|c|}
\hline ANO DE PUBLICAÇÃO & QUANTIDADE & $\%$ \\
\hline 2005 & 2 & - \\
\hline 2006 & - & - \\
2007 & 2 & 5,4 \\
2008 & 3 & 8,1 \\
2009 & 5 & 13,6 \\
2010 & 8 & 21,6 \\
2011 & 1 & 2,7 \\
2012 & 2 & 5,4 \\
\hline 2013 & 11 & 29,7 \\
2014 & 3 & 8,1 \\
\hline Total & - & - \\
\hline
\end{tabular}

Fonte: Portal de Periódicos da CAPES, 2016.

Ao analisar o ano de publicação dos artigos, identificamos que o artigo mais antigo foi publicado em 2005 e o mais atual em 2015. Sobre o ano de publicação do artigo mais antigo, podemos inferir que existe uma forte relação entre a data do I Congresso Internacional de Pesquisa (Auto)biográfica (CIPA) (2004) e o ano de publicação do artigo mais antigo (2005). Compreendemos que com a consolidação do CIPA, ${ }^{2}$ dos grupos de pesquisa, de publicações (em livros, artigos e revistas), dentre outras

2 O VII CIPA foi realizado de 17 a 20 de julho de 2016, em Cuiabá, Mato Grosso, e teve como tema "Narrativas (auto)biográficas: contextos e memórias - experiências e sentidos". Atualmente o CIPA está na sua oitava edição, que acontecerá em setembro de 2018 na Universidade Cidade de São Paulo, em São Paulo. atividades, houve uma maior dinâmica na produção e socialização de conhecimento, no campo da pesquisa (Auto)biográfica, expressa no aumento quantitativo da produção durante os anos investigados.

Sobre o volume de publicação, entre os anos de 2005 a 2015, houve um movimento que podemos explicar a partir de quatro momentos: 1) um primeiro momento em que se inicia o período de publicação, entre 2005-2007, com a publicação dos dois primeiros artigos em 2005, e entre 2006-2007 não houve a publicação de artigo relacionado ao campo da pesquisa (Auto)biográfica; 2) um segundo momento de ascendência, entre 2008-2011, quando houve 
o maior aumento progressivo na quantidade de artigos publicados no período analisado; 3 ) um terceiro momento, de declínio 2012-2013, com uma redução drástica na quantidade de artigos publicados e; 4) um quarto momento, 2014-2016, de oscilação da produção, em que 2014 registra a maior quantidade de artigos publicados, contudo, no ano de 2015, houve uma redução de quase um terço dos artigos e, no ano de 2016, até o momento da coleta, não identificamos artigos publicados.

Outro aspecto que observamos na análise dos artigos refere-se aos periódicos em que essas produções estavam anexadas. A Tabela 3, a seguir, apresenta a lista dos periódicos e a quantidade de artigos encontrados em cada um.

Tabela 3 - Distribuição dos principais periódicos identificados na análise dos artigos

\begin{tabular}{|c|c|c|}
\hline PERIÓDICOS & $\begin{array}{l}\text { QUANTIDADE DE } \\
\text { ARTIGOS }\end{array}$ & $\%$ \\
\hline $\begin{array}{l}\text { Acta Scientiarum. Education - Universidade Estadual de Maringá/ } \\
\text { UEM (Brasil) }\end{array}$ & 1 & 2,7 \\
\hline $\begin{array}{l}\text { Braziliam English Language Teaching - Pontificia Universidade } \\
\text { Católica do Rio Grande do Sul/PUC (Brasil) }\end{array}$ & 1 & 2,7 \\
\hline $\begin{array}{l}\text { Cadernos CEDES - Centro de Estudos Educação e Sociedade - } \\
\text { Universidade Estadual de Campinas/UNICAMP - (Brasil) }\end{array}$ & 2 & 5,4 \\
\hline $\begin{array}{l}\text { Civitas - Revista de Ciências Sociais - Faculdade de Filosofia e Ciên- } \\
\text { cias Humanas - Pontifícia Universidade Católica do Rio Grande do } \\
\text { Sul/PUC (Brasil) }\end{array}$ & 1 & 2,7 \\
\hline $\begin{array}{l}\text { Educação - Centro de Educação - Universidade Federal de Santa } \\
\text { Maria/UFSM (Brasil) }\end{array}$ & 1 & 2,7 \\
\hline $\begin{array}{l}\text { Educação - Faculdade de Educação - Pontifícia Universidade } \\
\text { Católica do Rio Grande do Sul/PUC (Brasil) }\end{array}$ & 10 & 27,1 \\
\hline $\begin{array}{l}\text { Educação em Revista - Faculdade de Educação - Universidade } \\
\text { Federal de Minas Gerais/UFMG (Brasil) }\end{array}$ & 1 & 2,7 \\
\hline $\begin{array}{l}\text { Educação Temática Digital - Faculdade de Educação - Universidade } \\
\text { Estadual de Campinas/UNICAMP (Brasil) }\end{array}$ & 2 & 5,4 \\
\hline $\begin{array}{l}\text { EDUCERE: La Revista Venezolana de Educacion - Faculdad de } \\
\text { Humanidades y Educación - Universidad de los Andes (Venezuela) }\end{array}$ & 1 & 2,7 \\
\hline $\begin{array}{l}\text { Estudios Pedagogicos - Faculdade de Filosofia y Humanidades - } \\
\text { Universidad Austral do Chile (Chile) }\end{array}$ & 3 & 8,1 \\
\hline $\begin{array}{l}\text { História da Educação - Universidade Federal do Rio Grande do Sul/ } \\
\text { UFRGS (Brasil) }\end{array}$ & 2 & 5,4 \\
\hline $\begin{array}{l}\text { Indagation Didactica - Centro de Investigação Didática e Tecnologia } \\
\text { na Formação de Professores - Universidade de Aveiro/UA (Portugal) }\end{array}$ & 1 & 2,7 \\
\hline $\begin{array}{l}\text { INTERFACE: Comunicação, Saúde e Educação - Universidade Esta- } \\
\text { dual Paulista/UNESP (Brasil) }\end{array}$ & 1 & 2,7 \\
\hline $\begin{array}{l}\text { International Journal of Psichology - International Union of } \\
\text { Psychological Science/IUPsyS (Organização multinacional) }\end{array}$ & 1 & 2,7 \\
\hline
\end{tabular}


Continuação...

\begin{tabular}{|c|c|c|}
\hline $\begin{array}{l}\text { Movimento - Escola de Educação Física, Fisioterapia e Dança - } \\
\text { Universidade Federal do Rio Grande do Sul/UFRGS (Brasil) }\end{array}$ & 1 & 2,7 \\
\hline $\begin{array}{l}\text { Psicologia, Ciência e Profissão - Conselho Federal de Psicologia } \\
\text { (Brasil) }\end{array}$ & 1 & 2,7 \\
\hline $\begin{array}{l}\text { Psicologia: Reflexão e Crítica - Univeridade Federal do Rio Grande } \\
\text { do Sul/UFRGS (Brasil) }\end{array}$ & 1 & 2,7 \\
\hline $\begin{array}{l}\text { REEC: Revista Eletrônica de enseñanza de las ciências sociales - } \\
\text { Universidade de Vigo (Espanha) }\end{array}$ & 1 & 2,7 \\
\hline $\begin{array}{l}\text { Revista Crítica de Ciências Sociais - Centro de Estudos Sociais - } \\
\text { Universidade de Coimbra (Portugal) }\end{array}$ & 1 & 2,7 \\
\hline $\begin{array}{l}\text { Revista Geográfica Acadêmica - Departamento de Geografia - } \\
\text { Universidade Federal de Roraima/UFRR (Brasil) }\end{array}$ & 1 & 2,7 \\
\hline $\begin{array}{l}\text { Revista Latinoamericana de Ciências Sociais - Universidad de } \\
\text { Manizales (Colômbia) }\end{array}$ & 1 & 2,7 \\
\hline Revista Mexicana de Investigación Educativa (México) & 1 & 2,7 \\
\hline $\begin{array}{l}\text { Tendências Pedagógicas - Faculdad de Formacion de Professorado } \\
\text { y Educacion - Universidad Autonoma de Madrid/UAM (Espanha) }\end{array}$ & 1 & 2,7 \\
\hline Total & 37 & 100 \\
\hline
\end{tabular}

Fonte: Portal de Periódicos da CAPES, 2016.

$\mathrm{Na}$ análise da Tabela 3, encontramos uma diversidade de 23 periódicos diferentes, em que os artigos estão publicados. Quando analisamos a distribuição destes 23 periódicos pelos países a que estão vinculados, temos a seguinte situação: 14 são do Brasil; dois são de Portugal e Espanha, cada um, e Chile, Colômbia, Venezuela e México apresentando um periódico cada. Dessa forma, houve um predomínio de países da América do Sul, mas encontramos trabalhos na América Central e Europa.

Sabemos que, devido ao caráter nacional do portal de periódico da CAPES, iríamos encontrar mais artigos vinculados a instituições brasileiras, contudo, esses dados somente endossam a quantidade de universidades e países que vêm discutindo e produzindo no campo da pesquisa (auto)biográfica.
Quando analisamos a distribuição dos artigos especificamente por periódico, encontramos uma maior quantidade, no periódico da revista Educação, da Pontifícia Universidade Católica do Rio Grande do Sul/PUC, representando 10 artigos anexados, cerca de $27,1 \%$ da amostra total. Em segundo lugar, identificamos a revista Estudios Pedagogicos do Chile, com três artigos publicados, cerca de 8,1\% do total.

Nos periódicos Cadernos CEDES, Educação Temática Digital e História da Educação, identificamos dois artigos em cada um, ou seja, cerca de 5,5\% da amostra total. 0 restante dos periódicos apresentou apenas um artigo publicado, representando $2,7 \%$ da amostra final. Identificamos também periódicos vinculados a organizações que têm vínculos com diferentes países, como foi o caso da International Jour- 
nal of Psichology. Houve também periódicos organizados por entidades de classe, como é o caso do Conselho Federal de Psicologia, que edita o periódico Psicologia, Ciência e Profissão, e do Conselho Mexicano de Investigacion Educativa e da Associação Científica de Pesquisadores Mexicanos, que publicam a Revista Mexicana de Investigación Educativa.

Contudo, houve preponderância dos periódicos vinculados às Universidades, devido ao caráter do portal de periódico da CAPES. As universidades que mais se relacionaram com os artigos analisados foram: Universidade Federal do Rio Grande do Sul/UFRGS e Pontificia Universidade Católica do Rio Grande do Sul/ PUC-RGS. Destacamos também a Universidade Estadual de Campinas/UNICAMP, a Universidade Estadual de São Paulo/UNESP e a Universidade Federal de Santa Maria/UFSM. Outro destaque importante deve-se à Universidade Federal de Roraima/UFRR, que foi a única universidade da região Norte e Nordeste do país.

As universidades de outros países, que apareceram em nossas análises, foram: a Universidade de Coimbra e a Universidad de Aveiro, em Portugal, a Universidad Austral do Chile, a Universidad Autonoma de Madri e a Universidad de Vigo, ambas na Espanha, a Universidad de los Andes, na Venezuela, e a Universidad de Marizales, na Colômbia.

Outro ponto que podemos destacar diz respeito aos centros, departamentos, escolas ou faculdades a que os periódicos estão vinculados. Identificamos uma variedade de campos do conhecimento em que os periódicos estavam vinculados, a saber: Ciências Humanas, Filosofia, Educação, Educação Física, História, Psicologia, Comunicação, Saúde, Ciências Sociais e Geografia. Percebemos, portanto, que mesmo apontando como critério de seleção dos artigos o vínculo com o campo da Educação, encontramos artigos em diferentes áreas do conhecimento. Este dado representa a difu- são e a inter/transdisciplinaridade ${ }^{3}$ em que o campo da pesquisa (Auto)biográfica se dispõe a produzir conhecimento.

Conforme já apontamos anteriormente, o critério de coleta e análise dos artigos foi a partir do portal de periódicos da CAPES e entendemos que o campo de pesquisa (Auto)biográfica é mais amplo, quantitativa e qualitativamente, indo além dos dados que encontramos, já que existem diversos periódicos, revistas, livros e editoras, em diferentes regiões do país, em que a discussão do campo da pesquisa (Auto)biográfica já se constitui de maneira consolidada. Como exemplo, podemos citar a produção do Grupo de Pesquisa (Auto)biografia, Formação e História Oral (GRAFHO), coordenado pelo professor Elizeu Clementino de Souza, situado na região Nordeste do Brasil, como um importante espaço de produção e socialização das discussões no campo da pesquisa (Auto)biográfica.

Especificamente sobre as temáticas dos artigos analisados, a Tabela 4, a seguir, apresenta a distribuição dos artigos segundo os principais temas discutidos. A sistematização dos diferentes tópicos temáticos foi realizada a partir das leituras e discussões, no campo da pesquisa (Auto)biográfica.

A organização por temas deu-se da seguinte forma: 1) pesquisa (auto)biográfica, métodos e fontes; 2) pesquisa (auto)biográfica, profissionalização e formação de professores; 3) pesquisa (auto)biográfica, vida e obra de educadores; 4) pesquisa (auto)biográfica e narrativas da infância e juventude; e 6) pesquisa (auto)biográfica, aspectos sociológicos e construção da identidade.

3 Em palestra realizada no dia 14 de julho de 2016, na mesa intitulada "Pesquisa (auto)biográfica: aspectos teórico-metodológicos", Maria da Conceição Passeggi colocou que a pesquisa (Auto)biográfica amplia-se, para além do campo inter ou transdisciplinar, apoiando-se no campo pós-disciplinar. Consideramos que essa variedade de campos do conhecimento, em que a pesquisa (Auto)biográfica vem produzindo, apresenta uma coerência com o pensamento levantado por Passeggi naquela ocasião. 
Tabela 4 - Distribuição dos artigos sobre Pesquisa (Auto)biográfica por eixo temático

\begin{tabular}{l|c|c}
\multicolumn{1}{c}{ Eixos Temáticos } & \multicolumn{2}{c}{ Total } \\
\cline { 2 - 3 } & Quant. & $\%$ \\
\hline Pesquisa (auto)biográfica, métodos e fontes & 9 & 24,3 \\
\hline Pesquisa (auto)biográfica, profissionalização e formação de professores & 13 & 35,2 \\
\hline Pesquisa (auto)biográfica, vida e obra de educadores & 4 & 10,8 \\
\hline Pesquisa (auto)biográfica e narrativas da infância e juventude & 5 & 13,5 \\
\hline Pesquisa (auto)biográfica, aspectos sociológicos e construção da & 6 & 16,2 \\
\hline identidade & 37 & 100 \\
\hline
\end{tabular}

Fonte: Portal de Periódicos da CAPES, 2016.

Identificamos que o eixo temático com o maior número de artigos foi o tópico "Pesquisa (auto)biográfica, profissionalização e formação de professor", com 13 artigos, representando cerca de 35,2\% da amostra total. Neste eixo, apareceram trabalhos que se apropriaram das narrativas das experiências vividas pelos professores em formação e a sua capacidade de contribuição no processo de profissionalização de cada um. Nesta análise, identificamos uma similaridade dos resultados deste trabatho com os resultados apontados por Sthepanou (2008), que aponta, em seu estudo sobre o estado da arte, o predomínio de trabalhos que discutem a formação de professores(as).

o segundo eixo com o maior número de trabalhos foi "Pesquisa (auto)biográfica, métodos e fontes", com nove artigos analisados, representando $24,3 \%$ do total. Neste grupo, identificamos artigos que discutiram: a) aspectos epistemológicos da pesquisa (auto)biográfica como, por exemplo, o conceito de formação e experiência; e b) aspectos técnicos e fontes diversas, a exemplo de artigos que refletiram sobre diferentes instrumentos de coleta e análise de dados.

O terceiro eixo com mais artigos foi "Pesquisa (auto)biográfica, aspectos sociológicos e construção da identidade", com seis artigos identificados, quantitativo que equivale a $16,2 \%$ da amostra global dos materiais. Nesses artigos, a partir das narrativas, foram debatidos o processo de migração, a emancipação social, expectativas profissionais e a construção da identidade docente.

O eixo "Pesquisa (auto)biográfica, narrativas da infância e juventude" foi o quarto tema mais discutido, com cinco artigos analisados, correspondendo a um percentual de 13,5\% da amostra total. O conjunto de artigos desse grupo versou sobre diferentes narrativas da infância e juventude de docentes, refletindo sobre os impactos dessas narrativas na construção da identidade docente e na prática pedagógica.

O quinto e último eixo, denominado de "Pesquisa (auto)biográfica, vida e obra de educadores" apresentou quatro artigos, correspondendo a $10,8 \%$ do total. Neste grupo, os artigos discutiram as contribuições de educadores, tais como: Maria de Lourdes Gastal, Ivan Fernandes Lima, Rodolfo Stavenhagen e outros renomados educadores do Rio Grande do Sul.

A Tabela 5, a seguir, apresenta os principais eixos temáticos dos artigos coletados por referência à experiência de professor ou de aluno. 
Tabela 5 - Distribuição dos eixos temáticos sobre Pesquisa (Auto)biográfica por referência à experiência de professor ou de aluno

\begin{tabular}{l|c|c}
\hline \multirow{2}{*}{ Eixos Temáticos } & \multicolumn{2}{c}{ TOTAL } \\
\cline { 2 - 3 } & Professor & Aluno \\
\hline Pesquisa (auto)biográfica, métodos e fontes & - & 1 \\
\hline $\begin{array}{l}\text { Pesquisa (auto)biográfica, profissionalização } \\
\text { e formação de professores }\end{array}$ & 7 & 5 \\
\hline $\begin{array}{l}\text { Pesquisa (auto)biográfica, vida e obra de } \\
\text { educadores }\end{array}$ & 4 & - \\
\hline $\begin{array}{l}\text { Pesquisa (auto)biográfica e narrativas da } \\
\text { infância e juventude }\end{array}$ & - & 5 \\
\hline $\begin{array}{l}\text { Pesquisa (auto)biográfica, aspectos } \\
\text { sociológicos e construção da identidade }\end{array}$ & 1 & 1 \\
\hline \multicolumn{1}{c|}{ Total } & 12 & 12 \\
\hline
\end{tabular}

Fonte: Portal de Periódicos da CAPES, 2016.

Os dados da Tabela 5 indicam que a quantidade de resumos referentes à experiência da condição docente é equivalente à quantidade dos achados da condição de aluno(a), com 12 referências cada um, dentre os 37 artigos analisados. Esses dados diferem dos resultados encontrados por Stephanou (2008), pois, em sua pesquisa, há uma maior incidência de referências à condição do professor(a). Podemos compreender esse movimento de aumento de interesse pela "escuta" de narrativas de aluno(a) como um "novo" viés para o campo da pesquisa (auto)biográfica, somando-se as narrativas de crianças, pais e jovens, dentre outros. É importante destacar que no cenário histórico das pesquisas em Educação, não é comum a atenção à escuta sensivel desses públicos.

Contudo, no que tange a uma análise por eixo temático, percebemos que, nos eixos
Pesquisa (auto)biográfica, profissionalização e formação de professores e Pesquisa (auto) biográfica, vida e obra de educadores, há uma maioria de artigos que relatam a experiência da condição do professor(a). Nos eixos Pesquisa (auto)biográfica e narrativas da infância $e$ juventude e Pesquisa (auto)biográfica métodos e fontes, há uma maior incidência de artigos que abordam a condição do aluno(a). No eixo Pesquisa (auto)biográfica, aspectos sociológicos e construção da identidade, há uma equivalência em relação à referência da condição de professor(a) e aluno(a) com uma incidência em cada eixo.

Outro aspecto que merece um destaque em nossa análise diz respeito ao corpus empírico dos artigos analisados. A Tabela 7, a seguir, apresenta a quantidade e a variedade do corpus empírico identificado nos artigos analisados. 
Tabela 7 - Distribuição do corpus empírico dos artigos analisados

\begin{tabular}{l|l}
\multicolumn{1}{c|}{$\begin{array}{c}\text { Corpus empírico } \\
\text { (documentos das pesquisas) }\end{array}$} & TOTAL \\
\hline $\begin{array}{l}\text { Narrativas/relatos (auto)biográficos } \\
\text { (orais ou escritos) }\end{array}$ & 22 \\
\hline Entrevistas não estruturada & 1 \\
\hline Entrevista em profundidade & 1 \\
\hline Histórias de vida & 4 \\
\hline Memoriais de Formação & 2 \\
\hline Análise compreensiva-interpretativa & 1 \\
\hline Método Etnográfico & 1 \\
\hline Rodas de conversa & 1 \\
\hline Grupo reflexivo & 1 \\
\hline Ateliês de escrita (auto)biográfica & 1 \\
\hline Entrevista (auto)biográfica & 1 \\
\hline Biografias educacionais & 1 \\
\hline Grupo colaborativo & 1 \\
\hline Desenhos & 1 \\
\hline Atividades Pedagógicas escritas & 1 \\
\hline Diários de aula & 1 \\
\hline Fotobiografias & 1 \\
\hline Videografias & 1 \\
\hline Filmes & 1 \\
\hline Portfólios & 1 \\
\hline Cartas & 1 \\
\hline Narrativas cênicas & 1 \\
\hline Fon: Portade Periodicos da CAPS, 2016. & 1 \\
\hline
\end{tabular}

Fonte: Portal de Periódicos da CAPES, 2016.

Percebemos, em relação ao corpus empírico apresentado nos resumos, uma diversidade de opções, fontes e estratégias metodológicas. Contudo, prevaleceram os seguintes documentos: narrativas/relatos (auto)biográficos orais e escritos, história de vida e memoriais de formação.

A Tabela 7 possibilita a compreensão dos inúmeros documentos que servem de suporte para o campo da pesquisa (auto)biográfica, tais como: desenhos, diários, fotografias, vídeos, filmes, portfólios, cartas, entrevistas, rodas de conversa, grupos reflexivos, dentre outros.

Em relação à amplitude de opções que o campo da pesquisa (auto)biográfica nos aponta, Stephanou (2008) apresenta que:

Enfim, se uma tendência geral quanto aos professores e à formação docente sobreleva no conjunto dos resumos, por outro lado, a variação institucional, nas fontes, autores e es- 
tratégias metodológicas confere um caráter de diversidade anteriormente referido, o que impede as generalizações. De qualquer modo, a tendência a ser afirmada é a ascensão do número de estudos que vêm se (pre)ocupando, nos últimos anos, com as histórias de vida e os relatos (auto)biográficos. (STEPHANOU, 2008, p. 38)

Percebemos, portanto, que nossos dados, em relação às principais temáticas discutidas e à diversidade de fontes para a pesquisa (auto)biográfica, apresentam similaridade com os dados apresentados por Stephanou (2008). Isso reflete a tendência contemporânea em torno de estudos sobre história de vida e narrativas (auto)biográficas.

\section{Apontamentos (in)conclusivos}

Inicialmente, consideramos, assim como Stephanou, que o conjunto de trabalhos analisados

[...] formaram um horizonte rico para compreender as opções, direções, escolhas e desatenções que temos produzido no campo da pesquisa na pós-graduação em Educação, particularmente, em história da educação, memória, autobiografias e história de vida. (2008, p. 22)

Apoiando-nos nessa assertiva, pensamos que esse movimento de análise do estado da arte no portal de periódicos da CAPES nos fez ampliar o horizonte das opções teóricas, das direções metodológicas, das escolhas técnicas, das articulações a diferentes campos do conhecimento, das lacunas e das possibilidades que a pesquisa (auto)biográfica nos apresenta. Nesse sentido, temos que ter o cuidado, ao elaborar um estudo de caráter do estado da arte, conforme aponta Stephanou, quando nos alerta que:

Depreende-se da leitura desses resumos que, embora reconheçam os direitos de expressão da subjetividade, assim como sua validade nas pesquisas em Educação, de outra parte não descuidam de questionar o imediatismo iden- titário, a armadilha do conceito de identidade universal e fixista e, portanto, de uma verdade essencial do sujeito, assim como a tendência à psicologização da existência. (2008, p. 38)

Em relação ao quantitativo de artigos e à utilização dos descritores, o descritor "narrativa(s) autobiográfica(s)" representou a maioria da amostra total, seguido de "pesquisa (auto) biográfica" e "pesquisa biográfica".

Ao analisar o ano de publicação dos artigos, identificamos que o artigo mais antigo foi publicado em 2005 e o artigo mais atual em 2015. No tocante à distribuição nacional dos 23 periódicos identificados, a maioria está vinculada ao Brasil, ademais encontramos artigos de países da América do Sul, América Central e Europa. A Universidade Federal do Rio Grande do Sul (UFRGS) e a Pontificia Universidade Católica do Rio Grande do Sul (PUC-RGS) foram as universidades que tiveram a maior frequência de citações, respectivamente.

Identificamos, portanto, múltiplos campos do conhecimento em que se vinculam os periódicos, a saber: Ciências Humanas, Filosofia, Educação, Educação Física, História, Psicologia, Comunicação, Saúde, Ciências Sociais e Geografia. Isso representa a capacidade de articulação que o campo da pesquisa (Auto)biográfica vem nos permitindo.

Em relação aos principais temas discutidos, a "Pesquisa (auto)biográfica, profissionalização e formação de professor" constitui-se da maioria dos trabalhos, seguido de "Pesquisa (auto)biográfica, métodos e fontes", "Pesquisa (auto)biográfica, aspectos sociológicos e construção da identidade", "Pesquisa (auto) biográfica, narrativas da infância e juventude" e "Pesquisa (auto)biográfica, vida e obra de educadores".

Acerca da experiência referente à condição docente e/ou do aluno(a), identificamos uma semelhança quantitativa nos artigos analisados. Contudo, compreendemos que há aumen- 
to pelo interesse de "escuta" nas narrativas de aluno(a), somando-se às narrativas de crianças, pais e jovens, dentre outros.

$\mathrm{Na}$ análise do corpus empírico, identificamos uma variedade de opções, fontes e estratégias metodológicas, prevalecendo as narrativas/relatos (auto)biográficos, orais e escritos, as histórias de vida e os memoriais de formação.

Dessa forma, entendemos que os resumos dos artigos analisados precisam de uma atenção potencializada, apenas exercitada introdutoriamente neste trabalho. Ou seja, necessitam de mais movimentos no caleidoscópio, para que possamos conferir outros arranjos e imagens sobre o objeto de estudo deste artigo; como sugestão, pode-se ampliar a área de conhecimento para além do campo da Educação, procurando verificar como tem se configurado o campo da Pesquisa (auto)biográfica com a

\section{Referências}

CONGRESSO INTERNACIONAL DE PESQUISA (AUTO) BIOGRÁFICA. Anais... Porto Alegre: PUCRS 2004.

CONGRESSO INTERNACIONAL DE PESQUISA (AUTO) BIOGRÁFICA. 2., 2006, Salvador. Anais... Salvador: EDUNEB, 2006.

CONGRESSO INTERNACIONAL DE PESQUISA (AUTO) BIOGRÁFICA. 3., 2008. Anais... Natal: UFRN, 2008.

CONGRESSO INTERNACIONAL DE PESQUISA (AUTO) BIOGRÁFICA. 7., 2016, Anais... Cuiabá: UFMT, 2016.

FERREIRA, Norma Sandra de Almeida. As pesquisas denominadas "estado da arte". Educação e Sociedade, ano, XXIII, n. 78, p. 257-272, ago. 2002. Disponível em: <http://www.scielo.br/pdf/es/v23n79/10857. pdf>. Acesso em: 23 jul. 2016.

MIGNOT, Ana Chrystina; SOUZA, Elizeu Clementino de. Modos de viver, narrar e guardar: diálogos cruzados sobre pesquisa (auto)biográfica. Revista Linhas, Florianópolis, v. 16, n. 32, p. 10-33, set./dez. 2015. Disponivel em: <http://www.revistas.udesc. saúde, a administração, a literatura e as artes, entre outros.

Sobre este assunto, não temos a intenção de esgotar o debate e nem de assumir estas análises como a verdade universal sobre o objeto. Assim:

Renunciar à possibilidade de discussão e de confrontação crítica pode levar à imposição de uma determinada verdade. Permitamos a desconfiança frente aos discursos da subjetividade, das narrativas de identidade, como construção de verdade do sujeito. Mas, sobretudo, continuemos insistindo na arte de pesquisar, pois afirmando os trabalhos do pensamento, afirmamos o direito à vida. (STEPHANOU, 2008, p. 40)

Assim, inspirados nessas palavras oferecemos este texto para partilhas, novas indagações, olhares curiosos, atentos e críticos, com a perspectiva de contribuir para o campo da pesquisa (auto)biográfica.

br/index.php/linhas/issue/view/453/showToc>. Acesso em: 7 de jul. 2016.

SOUZA, Elizeu Clementino de; SOUSA, Cynthia Pereira de; CATANI, Denice Barbara. A pesquisa (auto)biográfica e a invenção de si no Brasil. Revista FAEEBA - Educação e Contemporaneidade, Salvador, v. 17, n. 29, p. 31-42, jan./jun., 2008. Disponivel em: $<$ http:// www.uneb.br/revistadafaeeba/files/2011/05/numero29.pdf>. Acesso em: 7 de jun. 2016.

STEPHANOU, Maria. Jogo de memórias nas esquinas dos tempos: territórios e práticas da pesquisa (auto)biográfica na pós-graduação em Educação no Brasil. In: SOUZA, Elizeu Clementino de.; PASSEGI, Maria da Conceição. (Orgs.). Pesquisa (auto) biográfica: cotidiano, imaginário e memória. Natal: EDUFRN: São Paulo: Paulus, 2008. (Coleção Pesquisa (Auto)biográfica e Educação, v. 7. p. 19-53.

Recebido em: 21.12.2016

Aprovado em: 30.07 .2017 
Michael Daian Pacheco Ramos é doutorando em Educação pelo Programa de Pós-Graduação em Educação e Contemporaneidade da Universidade do Estado da Bahia (UNEB). Mestre em Educação pela Universidade Estadual de Feira de Santana (UEFS), Professor do curso de Educação Física da Universidade do Estado da Bahia, Campus IV, Jacobina. Pesquisador do Grupo de Pesquisa (Auto)biográfia, Formação e História Oral (GRAFHO). e-mail: michaeluneb@gmail.com

Rua Barra Paulista, 216, Cidade Nova, Feira de Santana/BA. CEP: 44053-256

Telefone: (75) 991847243

Rita de Cássia Magalhães de Oliveira é Mestre em Educação e Contemporaneidade pela Universidade do Estado da Bahia (UNEB) e doutoranda em Educação pelo Programa de Pós-Graduação em Educação e Contemporaneidade pela Universidade do Estado da Bahia (UNEB). Pesquisadora do Grupo de Pesquisa (Auto)biográfia, Formação e História Oral (GRAFHO). Professora da Secretaria de Educação do Estado da Bahia. e-mail: rcmagal@yahoo.com.br

Barra da Retiro, 152, Mangabeira, Feira de Santana/BA. CEP: 44056-528

Telefone: (75) 99210-6246

Maria Rita Santos é Mestre em Educação pela Universidade Estadual de Feira de Santana (UEFS) e Doutoranda em Educação pelo Programa de Pós-Graduação em Educação e Contemporaneidade pela Universidade do Estado da Bahia (UNEB). Bolsista CAPES. e-mail: mariaritinhasantos@hotmail.com

Rua B, caminho 18, casa 08, Feira VI, Feira de Santana/BA. CEP: 44034-292

Telefone: (75) 99192-3430 


\title{
APÊNDICE A \\ FICHA COM DADOS SOBRE O ESTADO DA ARTE DA PESQUISA (AUTO)BIOGRÁFICA \\ UTILIZANDO O DESCRITOR: \\ OPÇÃO (QUALQUER OU EXATO): \\ QUANTIDADE TOTAL DA AMOSTRA:
}

\author{
AMOSTRA 1 \\ TÍTULO DO TRABALHO: \\ AUTOR(ES): \\ TIPO DE PESQUISA: (ARTIGO, LIVRO, DISSERTAÇÃO OU TESE) \\ DATA DE PUBLICAÇÃO: \\ DADOS DO PERIÓDICO ANEXADO: \\ RESUMO:
}

PALAVRAS-CHAVE:

\section{APÊNDICE B}

\section{LISTA DE ARTIGOS SELECIONADOS PARA ANÁLISE}

Quadro 1 - Lista de artigos selecionados para análise utilizando o descritor abordagem (auto)biográfica

\begin{tabular}{|c|c|c|c|c|c|}
\hline \multicolumn{5}{|c|}{ UTILIZANDO O DESCRITOR ABORDAGEM (AUTO)BIOGRÁFICA } \\
\hline \multirow{2}{|c|}{ TíTULO } & AUTORES & PERIÓDICO & $\begin{array}{c}\text { Volume e } \\
\text { número }\end{array}$ & $\begin{array}{c}\text { ANO DE } \\
\text { PUBLICAÇÃO }\end{array}$ \\
\hline $\begin{array}{c}\text { Abordagem (auto)biográfica } \\
- \text { narrativas de formação } \\
\text { e de autorregulação da } \\
\text { aprendizagem reveladas em } \\
\text { portifólios reflexivos }\end{array}$ & $\begin{array}{c}\text { Lourdes Maria Bragagnolo } \\
\text { Ana Margarida da Veiga } \\
\text { Simão }\end{array}$ & $\begin{array}{c}\text { Educação - PUC - } \\
\text { Porto Alegre (RS) } \\
\text { (Brasil) }\end{array}$ & Vol. 34 (2) & 2011 \\
\hline 3 & $\begin{array}{c}\text { Sobre o conceito de formação } \\
\text { na abordagem (auto)biográfica }\end{array}$ & $\begin{array}{c}\text { Inês Ferreira de Souza } \\
\text { Bragança }\end{array}$ & $\begin{array}{c}\text { Educação - PUC - } \\
\text { Porto Alegre (RS) } \\
\text { (Brasil) }\end{array}$ & Vol. 34 (2) & 2011 \\
\hline 3 & $\begin{array}{c}\text { Tempos e memórias de } \\
\text { professoras-alfabetizadoras }\end{array}$ & $\begin{array}{c}\text { Cleuza Maria Sobral Dias } \\
\text { Maria Emilia Amaral Engers }\end{array}$ & $\begin{array}{c}\text { Educação - PUC - } \\
\text { Porto Alegre (RS) } \\
\text { (Brasil) }\end{array}$ & Vol.3 (57) & 2005 \\
\hline
\end{tabular}

Fonte: Elaboração própria, a partir da coleta no portal de periódicos da CAPES.

Quadro 2 - Lista de artigos selecionados para análise utilizando o descritor abordagem (auto)biográfica

\begin{tabular}{|c|c|c|c|c|c|}
\hline \multicolumn{5}{|c|}{ UTILIZANDO O DESCRITOR PESQUISA (AUTO)BIOGRÁFICA } \\
\hline TíTULO & AUTORES & PERIÓDICO & $\begin{array}{c}\text { Volume e } \\
\text { número }\end{array}$ & $\begin{array}{c}\text { ANO DE } \\
\text { PUBLICAÇÃO }\end{array}$ \\
\hline 5 & A experiência em formação & Maria da Conceição Passeggi & $\begin{array}{c}\text { Educação - PUC - } \\
\text { Porto Alegre (RS) } \\
\text { (Brasil) }\end{array}$ & Vol. 34 (2) & 2011 \\
\hline 5 & $\begin{array}{c}\text { Anotações teórico- } \\
\text { metodológicas do trabalho com } \\
\text { fontes visuais e audiovisuais } \\
\text { em pesquisas com Historia de } \\
\text { vida e Memoriais de Formação }\end{array}$ & $\begin{array}{c}\text { Maria Helena Menna Barreto } \\
\text { Abranão }\end{array}$ & $\begin{array}{c}\text { Educação - PUC } \\
\text { - Porto Alegre-RS } \\
\text { (Brasil) }\end{array}$ & Vol.39 (1) & 2014 \\
\hline $\begin{array}{c}\text { Campos y territórios de la } \\
\text { indagación (auto)biográfica em } \\
\text { Brasil: redes de investigación y } \\
\text { educación rural }\end{array}$ & Elizeu Clementino de Souza & $\begin{array}{c}\text { Revista Mexicana } \\
\text { de Investigação } \\
\text { Educativa (México) }\end{array}$ & Vol. 19 (62) & 2014 \\
\hline 7 & $\begin{array}{c}\text { Diálogos cruzados sobre } \\
\text { pesquisa (auto)biográfica: } \\
\text { análise compreensiva- } \\
\text { interpretativa e política de } \\
\text { sentido }\end{array}$ & Elizeu Clementino de Souza & $\begin{array}{c}\text { Educação - PUC } \\
\text { - Porto Alegre-RS } \\
\text { (Brasil) }\end{array}$ & Vol. 39 (1) & 2014 \\
\hline
\end{tabular}




\begin{tabular}{|c|c|c|c|c|c|}
\hline 8 & $\begin{array}{c}\text { Entre a vida e a formação: } \\
\text { pesquisa (auto)biográfica, } \\
\text { docência e profissionalização }\end{array}$ & $\begin{array}{c}\text { Maria da Conceição Passeggi } \\
\text { Elizeu Clementino de Souza } \\
\text { Paula Perin Vicentini }\end{array}$ & $\begin{array}{c}\text { Educação em } \\
\text { Revista } \\
\text { Faculdade de } \\
\text { Educação da UFMG } \\
\text { (Brasil) }\end{array}$ & Vol. 27 (1) & 2011 \\
\hline 9 & $\begin{array}{c}\text { Memória e (re)criação na } \\
\text { formação de professores: } \\
\text { trilhando caminhos }\end{array}$ & $\begin{array}{c}\text { Simone Silveira Cintra } \\
\text { Ana Angélica Albano }\end{array}$ & $\begin{array}{c}\text { Caderno CEDES - } \\
\text { UNICAMP (Brasil) }\end{array}$ & Vol. 30 (80) & 2010 \\
\hline 10 & $\begin{array}{c}\text { Memoriais de formação: o dizer } \\
\text { da experiência na escrita ou a } \\
\text { escrita como experiência }\end{array}$ & $\begin{array}{c}\text { Analice Dutra Pillar } \\
\text { Gilvânia Maurício Dias de } \\
\text { Pontes }\end{array}$ & $\begin{array}{c}\text { Educação - PUC } \\
\text { - Porto Alegre-RS } \\
\text { (Brasil) }\end{array}$ & Vol. 37 (3) & 2014 \\
\hline 11 & $\begin{array}{c}\text { Narrativas de crianças sobre as } \\
\text { escolas de infância: cenários } \\
\text { e desafios da pesquisa (auto) } \\
\text { biográfica }\end{array}$ & $\begin{array}{c}\text { Maria da Conceição Passeggi } \\
\text { et al. }\end{array}$ & $\begin{array}{c}\text { Educação-UFSM } \\
\text { (Brasil) }\end{array}$ & Vol. 39 (1) & 2014 \\
\hline
\end{tabular}

Fonte: Elaboração própria, a partir da coleta no portal de periódicos da CAPES.

Quadro 3 - Lista de artigos selecionados para análise utilizando o descritor abordagem autobiográfica

\begin{tabular}{|c|c|c|c|c|c|}
\hline \multicolumn{5}{|c|}{ UTILIZANDO O DESCRITOR ABORDAGEM AUTOBIOGRÁFICA } \\
\hline 12 & TíTULO & AUTORES & PERIÓDICO & $\begin{array}{c}\text { Volume e } \\
\text { número }\end{array}$ & $\begin{array}{c}\text { ANO DE } \\
\text { PUBLICAÇÃO }\end{array}$ \\
\hline $\begin{array}{c}\text { Clínica-escola: apoio } \\
\text { institucional inovador as } \\
\text { saúdicas de gestão e atenção na }\end{array}$ & $\begin{array}{c}\text { Olinda Maria de Fátima } \\
\text { Lechamn Saldanha } \\
\text { et al. } \\
\text { ensino-serviço }\end{array}$ & $\begin{array}{c}\text { Interface: } \\
\text { Comunicação, } \\
\text { Saúde e Educação - } \\
\text { UNESP (Brasil) }\end{array}$ & Vol. 18 (51) & 2014 \\
\hline
\end{tabular}

Fonte: Elaboração própria, a partir da coleta no portal de periódicos da CAPES.

Quadro 4 - Lista de artigos selecionados para análise utilizando o descritor pesquisa autobiográfica

\begin{tabular}{|c|c|c|c|c|c|}
\hline \multicolumn{6}{|c|}{ UTILIZANDO O DESCRITOR PESQUISA AUTOBIOGRÁFICA } \\
\hline & TÍTULO & AUTORES & PERIÓDICO & $\begin{array}{l}\text { Volume e } \\
\text { número }\end{array}$ & $\begin{array}{l}\text { ANO DE } \\
\text { PUBLICAÇÃO }\end{array}$ \\
\hline 13 & $\begin{array}{c}\text { Estratégias de acesso ao } \\
\text { Ensino Superior entre jovens } \\
\text { universitários com experiência } \\
\text { de trabalho na infância }\end{array}$ & Andrea Abreu Astigarraga & $\begin{array}{l}\text { Educação Temática } \\
\text { Digital - UNICAMP } \\
\text { (Brasil) }\end{array}$ & Vol. 12 & 2010 \\
\hline 14 & $\begin{array}{c}\text { Memória, narrativas e pesquisa } \\
\text { autobiográfica }\end{array}$ & $\begin{array}{l}\text { Maria Helena Menna Barreto } \\
\text { Abrahão }\end{array}$ & $\begin{array}{c}\text { História da } \\
\text { Educação - UFRGS } \\
\text { (Brasil) }\end{array}$ & Vol. 7 (14) & 2012 \\
\hline 15 & $\begin{array}{c}\text { O brincar em narrativas } \\
\text { autobiográficas: um estudo } \\
\text { intergeracional }\end{array}$ & $\begin{array}{l}\text { Maria de Fátima Vasconcelos } \\
\text { Costa }\end{array}$ & $\begin{array}{l}\text { Educação Temática } \\
\text { Digital - UNICAMP } \\
\text { (Brasil) }\end{array}$ & Vol. 12 & 2010 \\
\hline 16 & $\begin{array}{c}\text { Pesquisa Autobiográfica: } \\
\text { contribuições para a História } \\
\text { da Educação e de educadores } \\
\text { no Rio Grande do Sul }\end{array}$ & $\begin{array}{l}\text { Maria Helena Menna Barreto } \\
\qquad \text { Abrahão }\end{array}$ & $\begin{array}{l}\text { Educação - PUC } \\
\text { - Porto Alegre-RS } \\
\text { (Brasil) }\end{array}$ & Vol. $30(2)$ & 2005 \\
\hline
\end{tabular}

Fonte: Elaboração própria, a partir da coleta no portal de periódicos da CAPES

Quadro 5 - Lista de artigos selecionados para análise utilizando o descritor pesquisa biográfica

\begin{tabular}{|c|c|c|c|c|c|}
\hline \multicolumn{6}{|c|}{ UTILIZANDO O DESCRITOR PESQUISA BIOGRÁFICA } \\
\hline & TÍTULO & AUTORES & PERIÓDICO & $\begin{array}{l}\text { Volume e } \\
\text { número }\end{array}$ & $\begin{array}{c}\text { ANO DE } \\
\text { PUBLICAÇÃO }\end{array}$ \\
\hline 17 & $\begin{array}{l}\text { A narrativa e a formação de } \\
\text { professores }\end{array}$ & Marlene Rozek & $\begin{array}{c}\text { Indagatio Didáctica } \\
\text { Repositório Científico de acesso } \\
\text { aberto em Portugal - Universidade } \\
\text { de Aveiro (Portugal) }\end{array}$ & Vol. $5(2)$ & 2013 \\
\hline 18 & $\begin{array}{l}\text { A perspectiva biográfica na } \\
\text { pesquisa educativa: um olhar } \\
\text { sobre seus antecedentes, } \\
\text { tendências e possibilidades }\end{array}$ & Andrés Arguello & $\begin{array}{c}\text { Estudios Pedagógicos } \\
\text { (Valdivia) - Faculdade de Filosofia y } \\
\text { Humanidades - Universidad Austral } \\
\text { de Chile (Chile) }\end{array}$ & Vol. 40 (1) & 2014 \\
\hline
\end{tabular}




\begin{tabular}{|c|c|c|c|c|c|}
\hline 19 & $\begin{array}{l}\text { Alteridade na educação } \\
\text { em direitos humanos: um } \\
\text { estudo biográfico de Rodolfo } \\
\text { Stavenhagen }\end{array}$ & Andrés Arguello & $\begin{array}{c}\text { Estudios Pedagógicos } \\
\text { (Valdivia) - Faculdade de Filosofia y } \\
\text { Humanidades - Universidad Austral } \\
\text { de Chile (Chile) }\end{array}$ & Vol. 37 (1) & 2011 \\
\hline 20 & $\begin{array}{c}\text { Migração, pesquisa biográfica e } \\
\text { emancipação social: contributo } \\
\text { para a análise dos impactos da } \\
\text { pesquisa biográfica junto de } \\
\text { imigrantes }\end{array}$ & Elsa Lechner & $\begin{array}{l}\text { Revista Crítica de Ciências Sociais } \\
\text { - Centro de Estudos Sociais - } \\
\text { Universidade de Coimbra (Portugal) }\end{array}$ & (85) & 2009 \\
\hline 21 & $\begin{array}{l}\text { Narrativas e pesquisa } \\
\text { biográfica na sociologia } \\
\text { brasileira: revisão e } \\
\text { perspectivas }\end{array}$ & $\begin{array}{l}\text { Hermílio Santos } \\
\text { Patrícia de } \\
\text { Oliveira } \\
\text { Priscila Susin } \\
\end{array}$ & $\begin{array}{c}\text { Civitas - Revista de Ciências Sociais } \\
\text { - PUC/RS (Brasil) }\end{array}$ & Vol. 14 (2) & 2014 \\
\hline 22 & $\begin{array}{l}\text { O hermeneuta da geografia } \\
\text { alagoana: homenagem ao } \\
\text { geógrafo e professor Ivan } \\
\text { Fernandes Lima (Biografia) }\end{array}$ & $\begin{array}{l}\text { David } \\
\text { Christopher M. } \\
\text { de Amorim } \\
\text { Moises Calu de } \\
\text { Oliveira } \\
\end{array}$ & $\begin{array}{c}\text { Revista Geográfica Acadêmica - UFRR } \\
\text { (Brasil) }\end{array}$ & Vol. 2 (1) & 2008 \\
\hline 23 & $\begin{array}{l}\text { Revista do Ensino/RS e Maria } \\
\text { de Lourdes Gastal: duas } \\
\text { histórias em conexão }\end{array}$ & $\begin{array}{l}\text { Beatriz } \\
\text { Teresinha Daudt } \\
\text { Fisher }\end{array}$ & $\begin{array}{l}\text { História da Educação - UFRGS } \\
\text { (Brasil) }\end{array}$ & $\begin{array}{l}\text { Vol. } 14 \\
(30)\end{array}$ & 2011 \\
\hline
\end{tabular}

Fonte: Elaboração própria, a partir da coleta no portal de periódicos da CAPES.

Quadro 6 - Lista de artigos selecionados para análise utilizando o descritor abordagem biográfica

\begin{tabular}{|c|c|c|c|c|c|}
\hline \multicolumn{6}{|c|}{ UTILIZANDO O DESCRITOR ABORDAGEM BIOGRÁFICA } \\
\hline & TÍTULO & AUTORES & PERIÓDICO & $\begin{array}{l}\text { Volume e } \\
\text { número }\end{array}$ & $\begin{array}{l}\text { ANO DE } \\
\text { PUBLICAÇÃO }\end{array}$ \\
\hline 24 & $\begin{array}{l}\text { Formação de educadores } \\
\text { numa perspectiva de } \\
\text { construção do saber: } \\
\text { contributos da abordagem } \\
\text { biográfica }\end{array}$ & $\begin{array}{c}\text { Carmen Jesus Dores } \\
\text { Cavaco }\end{array}$ & $\begin{array}{c}\text { Caderno CEDES - UNICAMP } \\
\text { (Brasil) }\end{array}$ & Vol. 35 (95) & 2015 \\
\hline 25 & $\begin{array}{l}\text { O processo de integração } \\
\text { educacional do ponto de vista } \\
\text { de cinco jovens universitários } \\
\text { com deficiência visual do } \\
\text { Concepción }\end{array}$ & $\begin{array}{c}\text { Cecilia Avendaño } \\
\text { Bravo }\end{array}$ & $\begin{array}{c}\text { Estudios Pedagógicos } \\
\text { (Valdivia) - Faculdade de } \\
\text { Filosofia y Humanidades - } \\
\text { Universidad Austral de Chile } \\
\text { (Chile) }\end{array}$ & Vol. 40 (2) & 2014 \\
\hline 26 & $\begin{array}{l}\text { Formação em psicologia e } \\
\text { vulnerabilidade social: um } \\
\text { estudo das expectativas } \\
\text { de inserção profissional de } \\
\text { formandos }\end{array}$ & Silvia Maria Silveira & $\begin{array}{c}\text { Psicologia: Ciência e Profissão } \\
\text { - Conselho Federal de } \\
\text { Psicologia (Brasil) }\end{array}$ & Vol. $28(2)$ & 2008 \\
\hline
\end{tabular}

Fonte: Elaboração própria, a partir da coleta no portal de periódicos da CAPES.

Quadro 7 - Lista de artigos selecionados para análise utilizando o descritor narrativa autobiográfica

\begin{tabular}{|c|c|c|c|c|c|}
\hline \multicolumn{6}{|c|}{ UTILIZANDO O DESCRITOR NARRATIVA AUTOBIOGRÁFICA } \\
\hline & TÍTULO & AUTORES & PERIÓDICO & $\begin{array}{l}\text { Volume e } \\
\text { número }\end{array}$ & $\begin{array}{c}\text { ANO DE } \\
\text { PUBLICAÇÃO }\end{array}$ \\
\hline 27 & $\begin{array}{c}\text { Análisis de uma narrativa } \\
\text { autobiográfica professional en } \\
\text { la enseñanza superior }\end{array}$ & $\begin{array}{l}\text { Regiane Macuch } \\
\text { Carlinda Leite }\end{array}$ & $\begin{array}{l}\text { Tendências Pedagógicas - } \\
\text { Universidad Autonoma de } \\
\text { Madrid (Espanha) }\end{array}$ & (24) & 2014 \\
\hline 28 & $\begin{array}{l}\text { Narrativa autobiográfica } \\
\text { de estudantes de Química: } \\
\text { reflexões sobre a atividade } \\
\text { docente }\end{array}$ & Luciana Passos Sá & $\begin{array}{l}\text { REEC: Revista electrónica de } \\
\text { enseñanza de las ciências } \\
\text { - Universidade de Vigo } \\
\text { (Espanha) }\end{array}$ & Vol. $8(2)$ & 2009 \\
\hline 29 & $\begin{array}{l}\text { Relato autobiográfico } \\
\text { y subjetividade: uma } \\
\text { construcción narrativa de la } \\
\text { identidade personal }\end{array}$ & $\begin{array}{l}\text { Maria Gutiérrez } \\
\text { Fernandes }\end{array}$ & $\begin{array}{c}\text { EDUCERE: Revista } \\
\text { Venezolana de Educación - } \\
\text { Universidade de los Andes } \\
\text { (Venezuela) }\end{array}$ & (49) & 2010 \\
\hline 30 & $\begin{array}{l}\text { The making of autobiographical } \\
\text { memory: Intersections of } \\
\text { culture, narratives and identity }\end{array}$ & $\begin{array}{l}\text { Robyn Fivush } \\
\text { et al. }\end{array}$ & $\begin{array}{c}\text { International Journal } \\
\text { of Psychology - IUPSis } \\
\text { (Organização multinacional) }\end{array}$ & Vol. $46(5)$ & 2011 \\
\hline
\end{tabular}




\begin{tabular}{|c|c|c|c|c|c|}
\hline 31 & $\begin{array}{l}\text { Velhas histórias coladas à pele: } \\
\text { a importância das histórias de } \\
\text { vida na formação do professor }\end{array}$ & $\begin{array}{l}\text { Wolney Honório } \\
\text { Filho }\end{array}$ & $\begin{array}{l}\text { Educação - PUC - Porto } \\
\text { Alegre-RS (Brasil) }\end{array}$ & Vol. 34 (2) & 2011 \\
\hline 32 & $\begin{array}{l}\text { Avaliação na Educação } \\
\text { Física Escolar: reconhecendo } \\
\text { a especificidade de um } \\
\text { componente curricular }\end{array}$ & $\begin{array}{l}\text { Wagner dos Santos } \\
\text { et al. }\end{array}$ & Movimento - UFRGS (Brasil) & Vol. 21 (1) & 2015 \\
\hline 33 & $\begin{array}{l}\text { Grupo colaborativo e } \\
\text { formação docente: diálogos } \\
\text { (transformadores) com uma } \\
\text { professora universitária } \\
\text { iniciante }\end{array}$ & $\begin{array}{l}\text { Maria Aparecida de } \\
\text { Souza Perrelli } \\
\text { Luciana Virgili } \\
\text { Pedroso Garcia }\end{array}$ & $\begin{array}{l}\text { Acta Scientiarum. Education } \\
\text { - Universidade Estadual de } \\
\text { Maringá/UEM (Brasil) }\end{array}$ & Vol. $35(2)$ & 2013 \\
\hline 34 & $\begin{array}{l}\text { A formação dos professores } \\
\text { de língua estrangeira e suas } \\
\text { influências sob o viés das } \\
\text { narrativas autobiográficas }\end{array}$ & $\begin{array}{l}\text { Everton Vinicius de } \\
\text { Santa }\end{array}$ & $\begin{array}{c}\text { Brazilian English Language } \\
\text { Teaching Journal - PUC/RS } \\
\text { (Brasil) }\end{array}$ & Vol. 1 (1) & 2010 \\
\hline 35 & $\begin{array}{l}\text { Identidade profissional } \\
\text { docente: uma construçãao } \\
\text { histórico-sociocultural }\end{array}$ & $\begin{array}{l}\text { Gilson de Almeida } \\
\text { Pereira } \\
\text { Maria Emilia Amaral } \\
\text { Engers } \\
\end{array}$ & $\begin{array}{l}\text { Educação - PUC - Porto } \\
\text { Alegre-RS (Brasil) }\end{array}$ & Vol. 32 (3) & 2009 \\
\hline 36 & $\begin{array}{l}\text { A construção narrativa da } \\
\text { identidade }\end{array}$ & $\begin{array}{l}\text { Andre Guirland } \\
\text { Vieira } \\
\text { Margarida Rangel } \\
\text { Rodrigues } \\
\end{array}$ & $\begin{array}{c}\text { Psicologia: Reflexão e Crítica } \\
\text { - UFRGS (Brasil) }\end{array}$ & Vol. 27 (1) & 2014 \\
\hline 37 & $\begin{array}{l}\text { As jovens que abandonam } \\
\text { o ensino médio: rupturas e } \\
\text { pontos de não retorno }\end{array}$ & $\begin{array}{l}\text { Marcos Jacobo } \\
\text { Estrada Ruiz }\end{array}$ & $\begin{array}{l}\text { Revista Latinoamericana } \\
\text { de Ciencias Sociales - } \\
\text { Universidad de Manizales } \\
\text { (Colômbia) }\end{array}$ & Vol. $13(2)$ & 2015 \\
\hline
\end{tabular}

Fonte: Elaboração própria, a partir da coleta no portal de periódicos da CAPES. 